\title{
AS FORMAS DE VIVÊNCIA DA COMPETITIVIDADE PELOS ESTUDANTES NA GRADUAÇÃO EM ENFERMAGEM
}

\author{
HOW UNDERGRADUATE NURSING STUDENTS EXPERIENCE COMPETITIVENESS
}

\author{
LAS FORMAS DE VIVENCIAR LA COMPETITIVIDAD POR LOS \\ ESTUDIANTES EN EL PREGRADO DE ENFERMERÍA
}

\author{
Nathalia Medeiros Martins ${ }^{1}$ \\ Danielly Santos dos Anjos Cardoso ${ }^{2}$ \\ Laís Miranda Crispim Costa ${ }^{3}$ \\ Regina Maria dos Santos ${ }^{4}$ \\ Laíze Samara dos Santos ${ }^{5}$
}

Resumo $O$ estudo que deu origem a este artigo foi do tipo qualitativo, exploratório-descritivo, com o objetivo de analisar a vivência da competitividade pelo graduando de enfermagem. A coleta de dados foi realizada no período de março a maio de 2015. Os sujeitos foram vinte estudantes de graduação em enfermagem de duas instituições de ensino superior de Maceió, Alagoas. Utilizou-se uma entrevista semiestruturada para levantamento das informações e posterior análise temática. $\mathrm{O}$ referencial teórico adotado para análise dos dados partiu da concepção de competição de Caniato e Rodrigues, que tem suas bases teóricas e filosóficas na psicanálise freudiana e na teoria crítica da Escola de Frankfurt, em especial Adorno e Horkheimer. Percebeu-se que a competitividade é parte da vivência dos estudantes por ser considerada uma característica inerente ao ser humano, que naturalmente convive com ela no sistema capitalista. Esse comportamento competitivo pôde ser aguçado na graduação de acordo com o ambiente, a personalidade/índole e situações experienciadas. Constatou-se a existência de um conflito, pois os estudantes viam a competitividade como uma necessidade ante o 'mercado' de trabalho, mas a consideravam uma característica de caráter mais negativo. Palavras-chave educação em enfermagem; comportamento competitivo; enfermagem.

\begin{abstract}
The study that gave rise to this article was a qualitative, exploratory-descriptive one aimed at analyzing how nursing graduates experience competitiveness. Data collection took place between March and May 2015. The subjects were twenty undergraduate nursing students from two colleges in Maceió, state of Alagoas, Brazil. A semi-structured interview was used to collect the information and undertake the thematic analysis. The theoretical framework used to analyze the data came from Caniato and Rodrigues' views on competition, which has its theoretical and philosophical base Freudian psychoanalysis and the critical theory of the Frankfurt School, especially that of Adorno and Horkheimer. It was noted that competitiveness is part of the students' experience because it is considered an inherent characteristic of the human being, who, naturally, lives with it in the capitalist system. This competitive behavior might increase in undergraduate studies, according to the environment, to one's personality/nature, and to the situations experienced. It was noted there is conflict, since the students considered competitiveness as a necessity in view of the labor 'market,' but saw it as a more negative characteristic.
\end{abstract}

Keywords nursing education; competitive behavior; nursing. 


\section{Introdução}

A competição social é a base do modo de produção capitalista. Nota-se que desde os primórdios da organização social que conhecemos hoje a competição é valorizada de forma positiva. Contudo, sabemos que na contemporaneidade a competição se mostra como um imperativo categórico, cada vez mais acirrada a ponto de se transformar no ato de destruir a si e aos outros. Nessa direção, o competir tomou conta de todos os aspectos da vida das pessoas, enlaçando a construção e destruição da subjetividade humana (Caniato e Rodrigues, 2012).

No início dos anos 1990, os projetos neoliberais no contexto da educação privatista avançaram. As organizações multilaterais consideram a educação como atividade empresarial, e esse fato evidencia-se pelo incentivo à lucratividade, à competitividade e ao investimento no ensino privado, nas empresas preparatórias de vestibulares, indústrias de equipamentos técnicos e de informática e aproximação a grupos de interesse ligados à educação a distância, por exemplo (Robertson, 2012).

Como desdobramento, nas últimas décadas o número de escolas de enfermagem vem crescendo de forma preocupante em todo o país. Associado a esse fator, temos um 'mercado de trabalho' cada vez mais competitivo e precarizado, reflexo este em grande parte advindo do modelo econômico vigente, que propaga princípios neoliberais de individualismo exacerbado, egocentrismo, polivalência, tecnicismo, superespecialidades e fragmentação do ser, do saber e do fazer, além da busca desenfreada pelo lucro e o consumismo. Esse contexto influencia de forma significativa o mundo do trabalho, do trabalho em saúde e, consequentemente, o trabalho da enfermagem (Melo, 2010).

Nessa perspectiva, as instituições de ensino superior (IESs) assumem papel fundamental na mudança paradigmática que se deseja alcançar na formação dos futuros trabalhadores da saúde, especialmente enfermeiros, pois contribuem não só para a construção de um perfil de seres produtivos para determinada área no mundo do trabalho como também, principalmente, para a formação de uma massa crítica, reflexiva, humanística e ética de cidadãos (Anjos, 2013).

Assim, buscou-se refletir de forma mais ampliada sobre a temática de maneira a vislumbrar estratégias de superação da lógica mercantilista dos direitos sociais, principalmente da formação em saúde comprometida com as necessidades da população e a consolidação do Sistema Único de Saúde (SUS).

\section{Caminho percorrido}

A pesquisa aqui apresentada foi do tipo qualitativa, exploratório-descritiva, e teve como objetivo analisar a vivência da competitividade pelo graduando de enfermagem. O estudo foi realizado de setembro de 2014 a agosto de 2015 
em dois cursos de graduação em enfermagem de Maceió, Alagoas: um de caráter público e outro privado.

Os sujeitos da pesquisa foram estudantes regularmente matriculados nos cursos de graduação em enfermagem de todos os períodos das IESs participantes, totalizando vinte entrevistados escolhidos aleatoriamente e identificados por pseudônimos mediante a utilização de cores. A aproximação dos sujeitos ocorreu inicialmente pelo contato prévio das pesquisadoras com as IESs e, posteriormente, com agendamento das visitas para convite aos estudantes e entrevista após assinatura do termo de consentimento livre e esclarecido.

Para levantamento das informações utilizou-se uma entrevista semiestruturada para posterior análise temática, mediante leitura exaustiva e detalhada das entrevistas transcritas na íntegra e a construção de sínteses dos temas encontrados para a formação dos núcleos de sentido. O critério para suspensão da coleta de dados se deu pela identificação da saturação dos dados caracterizada pela repetição das mensagens cêntricas contidas nas falas dos entrevistados (Minayo, 2010).

O referencial teórico adotado para análise dos dados partiu da concepção de competição de Caniato e Rodrigues (2012), que tem suas bases teóricas e filosóficas na psicanálise freudiana e na teoria crítica da Escola de Frankfurt, em especial Adorno e Horkheimer. Dessa forma, entendeu-se aqui que competir significa verdadeiramente esvaziar-se, negar-se como indivíduo-sujeito, sujeitar-se às injunções perversas do capitalismo flexível, que retira a possibilidade do desenvolvimento da solidariedade e do acolhimento entre os homens. Portanto, o indivíduo precisa manter grande distância/vantagem dos outros, pois todos podem lhe tomar o lugar (Caniato e Rodrigues, 2012).

Partiu-se do pressuposto de que os estudantes já vivenciam esse comportamento competitivo cotidianamente, pois somos influenciados pelo modelo econômico vigente e sofremos suas consequências mais explícitas ou subliminares. Assim, procuramos saber como os estudantes vivenciavam essa competitividade na graduação em enfermagem e seus possíveis desdobramentos.

Por ser uma pesquisa que envolveria seres humanos, de acordo com os preceitos éticos e legais contidos na resolução n. 196/96 do Conselho Nacional de Saúde, ela foi encaminhada ao Comitê de Ética em Pesquisa da Universidade Federal de Alagoas, recebendo parecer favorável por meio do protocolo n. 788414 e certificado de apresentação e apreciação ética (CAAE) n. 35533414.2.0000.5013.

\section{Apresentação e discussão das vivências identificadas}

Os participantes deste estudo, em sua maioria, pertenciam ao gênero feminino, solteiros e com média de idade entre 18 e 26 anos. A vivência dos estudantes expressa nas entrevistas possibilitou a identificação de três categorias marcantes a todo momento na fala da maioria dos participantes, aqui apresentadas. 


\section{A competitividade: característica inerente à condição humana}

Desde o surgimento da vida na terra, o caráter competitivo esteve em evidência. A luta pela sobrevivência sempre caracterizou o comportamento dos seres vivos, incluindo-se aí o ser humano (Carvalho, 2009). A justificativa da competição como característica naturalmente humana estaria no seu sentido oposto se considerarmos que o homem fazia parte dessa própria natureza e necessitava dominá-la e superá-la para se manter, por isso se confundia com ela (Oliveira, 2010). Essa perspectiva pôde ser observada na fala a seguir:

Para mim essa competitividade existe em todos os cursos, pois independe da área, e sim da natureza humana, pois ser competitivo é algo que pertence ao ser humano (Vinho).

O cenário familiar é contexto de construção de práticas culturais; corresponde ao primeiro núcleo de aprendizado de muitos conhecimentos e crenças que são construídos, compartilhados e imitados, onde se transmitem as primeiras regras e valores associados ao convívio social da escola ou trabalho ou ainda à hereditariedade (Roehrs, Lenardt e Maftum, 2008; Castro, 2012). Como expressaram alguns dos entrevistados:

(...) todo comportamento que exercitamos passa se incorporar na personalidade (Salmon).

A competitividade faz parte da personalidade de algumas pessoas (Marrom).

$\mathrm{Na}$ atualidade, o capitalismo perpassa por todas as áreas; tudo se tornou mercadoria, se submeteu à lucratividade e acumulação de capital, ou seja, à lógica do mercado (Pereira, 2014). Dessa forma, um dos entrevistados remeteu a essa discussão a construção de valores importantes que passam a integrar a nossa personalidade, cultura e o nosso modo de ser e estar no mundo.

Acredito que assumimos essa postura competitiva não apenas pela criação e princípios individuais, como também pelas exigências e pela própria competitividade existente no mercado de trabalho (Amarelo).

Percebeu-se que o comportamento competitivo já estava presente na vida e no cotidiano dos entrevistados, antes mesmo de entrarem nas instituições de ensino superior, ou seja, fazia referência ao ambiente competitivo que vivenciaram antes da formação, nos cursos preparatórios e pré-vestibulares.

Existe uma grande competitividade para poder entrar na faculdade, e isso permanece (Verde). 
O mercado de trabalho hoje está muito concorrido, a competitividade já começa de agora (Azul).

O momento de seleção para ingresso no ensino superior coincide com a adolescência. Nessa etapa, ocorrem transformações físicas e psicológicas, pois é um período inusitado, no qual o jovem se depara com responsabilidades que não lhe eram atribuídas anteriormente. A conclusão do ensino médio e a procura por uma ocupação ou projeto profissional também estão presentes nesse momento. $\mathrm{O}$ ingresso na faculdade torna-se, assim, prioritário para muitos (Peruzzo et al., 2008).

Aqueles que conseguiram entrar no ensino superior, oriundos do ensino público ou do privado, como foi o caso de alguns dos sujeitos, atribuíram ao ambiente da formação/universidade a responsabilidade pela exacerbação do traço competitivo:

Porque muitos já são assim [competitivos] da vida inteira, e outros se acentuaram na universidade (...) e vão continuar sendo assim no seu campo de trabalho (Branco).

Desde a graduação a disputa pelo espaço individual acaba sendo estimulada desrespeitando princípios éticos e morais (Prata).

Desde que eu coloquei o pé na universidade que já é assim, é algo meio que programado, é induzido mesmo (...) a academia já provoca isso nos estudantes (Bege).

Na visão dos estudantes entrevistados, a competitividade, ao exacerbar-se, torna o ambiente da formação e o convívio com os colegas cada vez mais difícil e desleal, permeado pela busca incessante de superar-se a si e aos outros, o que se reflete em todos os aspectos das relações entre eles. Esse comportamento competitivo passa a ser considerado também como uma característica própria da personalidade dos sujeitos, a ponto de comprometer a ética e a moral na construção do perfil desse futuro trabalhador da enfermagem:

No entanto, quando a competitividade passa para o lado sombrio, como, por exemplo, trapacear ou de alguma forma prejudicar o outro, não é normal e não é compreensível. (...) O profissional é um reflexo do pessoal, eu não serei uma profissional honesta se sou desonesta fora do ambiente de trabalho (Pink).

Para muitos estudiosos da psicologia, a personalidade é compreendida como a constituição de um sistema composto por múltiplas e diferentes funções, sejam elas cognitivas, emocionais, aspectos que marcam o caráter e os desejos individuais, todas integradas determinam a maneira particular de ser e estar no mundo de cada pessoa (Bissoli, 2017). 
Neste sentido, segundo os participantes destacaram, a personalidade também se materializava com relação às omissões de informações ligadas a oportunidades de crescimento profissional:

Eu soube que iam ocorrer as provas de monitoria e saí avisando a todo mundo (...), mas teve gente que não avisou e eu soube que fez isso para diminuir a quantidade de concorrentes e poder adquirir a vaga (Verde).

Quando tem oportunidade de concurso, não avisam a ninguém, fazem em segredo, só avisam depois que já passou, ou então mostram que é melhor, tem mais artigos publicados (Azul).

Privando os demais de informações que os deixem em pé de igualdade como em uma guerra (Vermelho).

Percebemos nessas falas que a personalidade influencia diretamente as ações dos estudantes de enfermagem em relação a oportunidades e ao compartilhamento delas entre os colegas. Ou seja, há quem tenha um perfil já direcionado para competir de forma mais ou menos acirrada do que outros, o que por vezes dificulta as relações entre os colegas, gerando um clima tenso, suspeito e sem ajuda mútua.

Em contrapartida, percebe-se que alguns participantes consideraram que a competitividade pode ter uma vertente positiva, por estimular a busca pelo conhecimento, qualificação e crescimento profissional. Esse pensamento é legítimo se olharmos o que o paradigma produtivista nos impõe, pois vivemos numa sociedade - como afirma Mészáros (2008) - que se organiza em torno de um modelo econômico que tem no lucro, na competição, no consumo e no individualismo seus fundamentos.

Numa turma em que ninguém quer crescer, você não é incentivado a crescer, quando você vê as pessoas correndo atrás é bom (Lilás).

Vejo a competitividade de forma positiva para o crescimento pessoal e profissional, de modo que a mesma gera um estímulo e foco para o alcance dos objetivos, bem como promove a busca para o aperfeiçoamento das atribuições do enfermeiro na rotina estressante e corrida (Amarelo).

Vale ressaltar que esse comportamento competitivo, por um lado, incita ao aperfeiçoamento e à busca de melhores resultados e metas, mas, por outro, produz desigualdades, exclui e segrega. Dessa forma, os indivíduos precisam manter grande distância uns dos outros, pois todos podem lhes tomar o lugar. 
No entanto, será possível desenvolver uma competição solidária? Na vertente empreendedora, como reforça (Coan, 2014), fala-se e pratica-se uma cultura que acredita na necessidade de mudança - não do sistema, mas das pessoas. Para disseminar esse consenso de um capitalismo humanizado ou com rosto humano, utilizam-se princípios e argumentos frágeis na perspectiva de que não buscam explicar as contradições sociais intrínsecas a esse modelo econômico, nem a sua superação; apenas servem para enquadrar as pessoas e trabalhadores ao atual modelo societário.

Com relação às práticas pedagógicas no contexto da formação, um dos entrevistados atribuiu parte da responsabilidade na transferência de princípios e comportamentos competitivos à postura que alguns dos docentes assumem na academia:

Provavelmente a competitividade é influenciada pelos exemplos visualizados nas atitudes dos docentes da própria escola (Prata).

(...) o estímulo muitas vezes vem dos próprios professores para adquirir a questão de certificados para residência, especialização, mestrado. Quem tem um melhor currículo provavelmente poderá adquirir mais fácil, mais rápido, essas oportunidades (Bege).

As mudanças paradigmáticas no âmbito da educação perpassam por vários aspectos, e a formação do professor deve ser uma das prioridades. O professor deve assumir uma formação mais que técnica e científica, também ética para os futuros estudantes/enfermeiros, voltada especialmente para a necessidade social (Guareschi e Kurcgant, 2014).

Alguns dos participantes do estudo declararam a preocupação dos colegas em sobressair em relação aos demais da turma com a intenção de se destacar aos olhos do professor em busca de melhores conceitos, desviando o foco do processo de ensino-aprendizagem. Além disso, destacaram a questão do sistema avaliativo pelo seu caráter punitivo, que ranqueia e nivela a turma, estimulando assim a competitividade em vez da cooperação, da solidariedade e do crescimento coletivo.

Alguns componentes do grupo sempre buscam mostrar aos professores que sua postura e apresentação dos conteúdos estão melhores com o objetivo de obter nota maior que o outro e não de aprendizado em conjunto para o crescimento individual dos seus colegas de profissão também (Salmon).

Nem sempre a nota significa verdadeiramente o que você aprendeu (Bronze).

Historicamente, a formação dos profissionais de saúde tem sido pautada pelo uso de metodologias conservadoras, sob forte influência do neoliberalis- 
mo, baseado na fragmentação e redução do ser. Com a constante valorização das avaliações punitivas e categóricas, em detrimento das formativas, compreendidas como estratégias de ensino-aprendizagem que valorizam a troca de conhecimentos, saberes e experiências entre professor e estudantes. Essa formação cria assim um verdadeiro ranking de avaliação e desempenho, diversas vezes injusto e desleal (Anjos, 2013).

\section{Quem não compete não quer crescer, está fora do contexto}

Convivemos com um mercado explícito das instituições privadas de saúde e educação que priorizam a quantidade em detrimento da qualidade necessária para a formação de enfermeiros. Nas últimas décadas, o número de escolas de enfermagem vem crescendo de forma desenfreada. Dados de 2004 do Instituto Nacional de Estudos e Pesquisas Educacionais Anísio Teixeira, do Ministério da Educação (Inep/MEC), indicam que a área da enfermagem contava com 415 escolas/cursos (Instituto Nacional de Estudos..., 2006). Esse quantitativo passou para 838 em 2012, com 80,19\% na rede privada e $46,30 \%$ na região Sudeste. Tal variação evidencia que a expansão se deu, prioritariamente, na rede privada e na região Sudeste.

Esse aspecto foi identificado na fala dos estudantes participantes da pesquisa, quando relataram a preocupação com o número cada vez mais elevado de escolas de graduação em enfermagem, principalmente no setor privado. Logo, a política de expansão de cursos/vagas na área da saúde/enfermagem pode ter implicações danosas na efetivação de um processo de aprendizagem eficaz e de qualidade, limitando as oportunidades para a formação voltada para as dimensões do cuidado em saúde e para as relações que se estabelecem no ato de cuidar e na construção de uma atenção integral no âmbito das unidades de saúde (Fernandes, 2012).

Não sei em outros estados, mas aqui está muito saturado, a gente vê uma faculdade em cada esquina (Vinho).

Também é relacionado ao grande número de escolas, estão sendo formados muitos enfermeiros, aí gera uma concorrência forte aí (Laranja).

(...) como tem muitas escolas de enfermagem, então parece que por ter muitos profissionais, o pessoal se sente na obrigação de ser o melhor, até porque muitos já ficaram pra trás (Lilás).

O quantitativo dos cursos de graduação em enfermagem no estado era de oficialmente 12 instituições de ensino superior, totalizando 14 cursos credenciados, pois existia mais de um curso credenciado para duas das IESs. Desses cursos identificados, três localizavam-se no interior, um era de ensino supe- 
rior bacharelado na modalidade a distância e um na modalidade licenciatura; os demais se situavam na cidade de Maceió e eram da modalidade bacharelado presencial (Anjos, 2013). Ao atualizar esses dados pelo portal do e-MEC em outubro de 2015, totalizavam 15 cursos.

É notável que essa expansão venha ocorrendo de forma desarticulada com os cenários de pesquisa, extensão e prática profissional, o que se reflete na construção limitada do perfil de enfermeiros que estão sendo formados, bem como na valorização da competitividade por esse mercado da formação que é excludente, injusto, desleal e desumano. Assim, destaca-se o acelerado processo de desenvolvimento pelo qual alguns países vêm passando nas últimas décadas, exigindo que os profissionais das diversas áreas de atuação ingressem no 'mercado de trabalho' com uma nova visão de mundo, em que estejam presentes valores como competência, crescimento mútuo, atitude positiva, compromisso, honestidade, autodisciplina e liderança (Sousa e Barroso, 2009). A estreita relação da competitividade com a construção dessas características no perfil do enfermeiro se expressou na seguinte fala:

Um indivíduo que em sua formação formou pequenos grupos, privou os demais de informações com o intuito de sobressair aos demais, goza da plena incapacidade de ser líder, e isso influencia negativamente no futuro enfermeiro (Vermelho).

Na fala de alguns estudantes entrevistados, mesmo implicitamente, pudemos notar que a exclusão era considerada parte do dia a dia deles e que a luta pela conquista de melhores resultados, postos de trabalho ou posição social justificava naturalmente a necessidade de ser superior ou o seu insucesso:

Não me considero competitivo, porque se tem algo disponível comunico aos meus colegas, porque o que tem que ser nosso será, e a disputa, que vença quem realmente está preparado (Bege).

Associado a esse fator, percebeu-se que muitos estudantes citaram a questão da competitividade como sinônimo de superação pessoal, por isso não se consideravam competitivos. Contudo, a ideia de superioridade, autossuficiência e autoconfiança perante os demais estava subliminarmente presente - pois já que sou tão qualificado, não tenho receio ou necessidade de competir com os demais, visto que esses não estão no mesmo patamar que eu, logo não me alcançarão; dessa forma, só preciso competir e me preocupar comigo mesmo.

Para tanto, destaca-se aqui que a competição a que os indivíduos estão submetidos não diz respeito à busca da perfeição na execução de alguma habilidade humana, a um movimento de reconhecimento dos próprios limites e desenvolvimento dos potenciais. Ao contrário, é uma competição em que o 
que prevalece é a superação e o distanciamento do outro (Caniato e Rodrigues, 2012), como pudemos constatar nas falas:

Tento ajudar mais do que competir, tento competir comigo mesma (Preto).

Considero-me objetivo, minha competitividade diz respeito a me superar, porém tenho tendência de, quando em grupo, ser alguém mediano para me igualar ao máximo de pessoas ao meu redor, pois acredito que dessa forma é mais fácil alcançar grandes objetivos para o coletivo (Vermelho).

Poderíamos considerar esse comportamento similar a uma ação cooperativa que visa ao crescimento coletivo e não apenas ao individual. Outra vertente teórica ressalta que a competição não é algo natural nas pessoas, e sim comportamento adquirido, destacando a cooperação como valor vivenciado na vida cotidiana do povo há muito tempo. Salienta também que na maioria das vezes somos levados a pensar que a maneira de competir corretamente é aquela em que precisamos sempre vencer a qualquer custo (Silva e Silva, 2011).

Além disso, como constatado pelos participantes do estudo aqui apresentado, há quem queira se mostrar superior por meio da competitividade relacionada a bens materiais, classe e status social. Os bens materiais podem ser uma forma de se mostrar e se sentir em superioridade, deixando por vezes o conhecimento em segundo plano, o que nos mostra o quanto o 'ter' em detrimento do 'ser' é característica marcante em nossa sociedade consumista e materialista. Assim, destacaram-se as falas:

Alguns alunos querem ser melhores que os outros, e eu acho que até por classe social, por questão financeira, mas na realidade não é assim, a competitividade se dá através do conhecimento (Roxo).

Porque cada um quer ser melhor que o outro, quer ter mais poder que o outro, só que todos são iguais, acho que ninguém é melhor do que ninguém, todo mundo é igual (Rosa).

Nesse contexto, a competição como fenômeno social relaciona-se à atividade do homem, à relação de concorrência pela posse e usufruto de bens. Para que ela ocorra, deve existir algo que não é compartilhado, algo que só alguns têm o privilégio de possuir. A sociedade em que vivemos se organiza justamente pautada na desigualdade: um tem e os outros não têm (Caniato e Rodrigues, 2012).

Assim, percebemos como essa realidade e esse sentimento de exclusão estão implícitos na fala dos estudantes, e que por vezes o 'ter' está apenas relacionado a bens materiais, e não ao conhecimento. Como demonstrou a fala: 
Em momentos de avaliações na hora da entrega, né, das notas e principalmente nos trabalhos, porque não se dedicam tanto, mas querem ser melhores do que o outro e acabam se atrapalhando (Rosa).

A competitividade na maioria dos casos tem raízes na insegurança pessoal, podendo ter sua origem em sentimentos negativos como não aceitação do sucesso alheio, inveja, necessidade excessiva de poder, prestígio, status ou visibilidade social (Bazzi, 2009). Para tanto, alguns estudantes viam a competitividade como uma forma de buscar crescimento, considerando-se perseverantes e determinados:

É importante buscar o melhor, não para ser melhor do que ninguém, nem passar por cima de ninguém, mas para crescer na vida e como profissional (Cinza).

Eu acredito que se for uma competitividade que você não queria passar por cima das outras pessoas, eu acho que você pode se dar bem, porque você se esforça para dar o seu melhor, e isso vai acarretar numa boa formação profissional (Dourado).

Segundo os estudantes, na luta pela vida, em que só os mais bem adaptados sobrevivem, ideologicamente naturaliza-se o discurso da competição e a conclusão de que essa luta é necessária para se fazer a 'evolução' do ser humano, uma vez que só os 'bem-equipados' geneticamente conseguirão perpetuar-se, legitimando a competição predatória que produz a desigualdade e a exclusão social (Caniato e Rodrigues, 2012).

Embora a competitividade transite por uma concepção de educação que objetiva o fortalecimento e a reprodução do status quo, permeada pela ideia de mercantilização, inclusive respaldada pela atual política educacional brasileira, é importante ressaltar aqui a existência de uma concepção social de educação que visa não só à reversão desse modelo hegemônico educacional e de sociedade posto, mas também à justiça social mediante a ampliação de oportunidades educacionais e diminuição das desigualdades sociais.

Em relação às desigualdades sociais e à falta de oportunidades durante a graduação, alguns participantes ressaltaram:

Para quem está sofrendo, vamos dizer, certo bullying é ruim, mas para quem está adquirindo, está fluindo, é bom (Bege).

Nas atividades complementares do curso da universidade, tem muita gente que quer fazer tudo, quer ser de PET [Programa de Educação Tutorial] projetos, e acaba deixando muitas pessoas sem ter oportunidades (Laranja).

A problemática das desigualdades educacionais foi evidenciada ainda nos anos 1960 por Pierre Bourdieu e ressaltada por Valle (2013), ao citar Bourdieu 
e Passeron em seus escritos, quando afirma que as chances de acessar o ensino superior resultam de uma seleção que, ao longo do percurso escolar, se exerce com um rigor desigual segundo a origem social dos sujeitos.

As desigualdades escolares resultam de desigualdades sociais, e a desigualdade social é uma condição inerente ao próprio sistema capitalista, no qual um pequeno grupo de pessoas detém os meios de produção e o capital financeiro, enquanto a grande maioria da população é possuidora apenas de sua força de trabalho (Ferreira e Latorre, 2012).

Para tanto, pudemos evidenciar na fala de alguns entrevistados a forte influência que o sistema capitalista exerce sobre as pessoas, tanto em suas condições socioeconômicas e culturais quanto no modo como faz com que os seus princípios acabem se tornando parte dos princípios delas mesmas, como forma de sobrevivência dentro do modelo econômico.

Eu mesmo sou assim, se alguém está querendo ser mais do que eu, eu não quero ficar por baixo daquela pessoa, eu quero ser mais (Roxo).

Em relação a momentos de provas, estágios, trabalhos, tudo, tipo a gente percebe que todo mundo quer ser melhor, ninguém mede esforços para passar por cima de ninguém, entende? O que importa é você estar chamando atenção, se destacando (Vinho).

Observo as pessoas quererem ser e mostrarem ser melhores que as outras, falta de ajuda mútua para o crescimento do outro, só visam o crescimento de si próprio (Salmon).

Esses sujeitos terminam por esvaziar e privatizar os espaços outrora públicos, o que prejudica sobremaneira a socialização e a participação coletiva. Nesse sentido, o modo de produção capitalista determina o tipo de subjetividade do sujeito, no sentido das diferentes formas de 'individualização' decorrentes do individualismo liberal (Sousa, 2012).

O aumento da competição e do egoísmo acompanhou o surgimento e a consolidação do sistema capitalista. O liberalismo tornou-se o princípio basilar da sociedade do capital, em que todos os indivíduos são livres para buscar os seus próprios interesses por meio de suas atitudes egocêntricas, enaltecendo-se a liberdade individual na perspectiva de que a ação humana é movida unicamente pelos próprios interesses e motivações (Mattos, 2011); (Freitas e Lima, 2013). Tal realidade aqui enfatizada pôde ser constatada nas falas:

Quero estar melhor, melhorar sempre cada vez mais (Rosa).

A gente já entra no curso com esse pensamento de querer ser o melhor para conseguir seu lugar ao sol (Verde). 
Cada um quer chamar mais atenção e ser melhor do que o colega, em tudo, nas provas, concorrência de monitoria, projetos, notas, tudo que envolve currículo (Cinza).

A nova qualificação que o avanço tecnológico vem proporcionando para os trabalhadores, ao mesmo tempo que as novas formas de organização do trabalho baseadas nesses avanços, tem exigido um perfil de trabalhadores com maior escolaridade (politécnica) e características polivalentes, configurando estas últimas motivo de preocupação, por serem regidas pela lógica do capital e, portanto, da exclusão social e alienação.

A cultura neoliberal de massas utiliza a mídia como veículo para difundir e moldar, sob pressão, esse processo de individualização, competitividade e fuga da subjetividade, levando a pessoa a ser instigada a todo momento a se destacar da multidão, ser diferente, superior, a melhor (Scherer, 2011; Possoli, 2005). Tal naturalização se observou nas falas:

Todos somos competitivos, vivemos no capitalismo. Quem não compete não quer crescer, está fora do contexto (Rosa).

(...) todo mundo quer ser competitivo, pois satisfará a si mesmo, algo supernormal, pois todos necessitam de dinheiro (Vinho).

Sou competitiva, e todo mundo tem que ser, porque se você deixar os outros passarem por você e tal, você não lutar, não procurar, nunca vai sair de onde está (Bege).

Na contemporaneidade, em que o consumo de mercadorias parece tomar todas as esferas da vida dos indivíduos, a inveja aparece como um elemento de adesão destes à competição e, principalmente, ao consumismo. Dessa forma, o comportamento competitivo acaba por ser naturalizado, introjetado, apropriado em nossa sociedade, acompanhando as crescentes exigências do mercado de trabalho por qualidade e produtividade (Caniato e Rodrigues, 2012), conforme as falas a seguir:

A questão do mercado de trabalho também que pede isso, pede que você seja bom, tenha conhecimento (Laranja).

Sou muito competitiva em parte influenciada pelo próprio sistema (Amarelo).

Isso é normal, cada um quer seu espaço no mercado de trabalho, e sempre existe uma competitividade entre os alunos (Verde).

A diferença entre a educação implementada na graduação e a exigência e as condições precárias do mercado de trabalho tem causado dificuldades 
aos egressos na adequação deles em sua vida profissional (Canever et al., 2014). As notificações de erro da enfermagem são de conhecimento público e muitas vezes podem ser prevenidas. Dentre as possíveis causas da ocorrência desses erros, podemos citar, além da formação: falta de atenção, sobrecarga de trabalho, deficiência na comunicação entre os componentes da equipe, e até mesmo o preparo inadequado dos trabalhadores dentro do próprio serviço para atuar nas especificidades das diversas áreas de atenção à saúde (Borges e Peres, 2013).

\section{Sou competitiva, mas eu ajudo as pessoas}

O conflito foi uma questão constantemente presente e perceptível na fala da maioria dos entrevistados. Conflito entre aquilo que eu sou e o que devo ser. Conflitos que a competitividade traz por consequência, permeando as relações pessoais, sociais e de trabalho, pois o modelo econômico e de sociedade em que vivemos imprime nas pessoas suas características, princípios e valores.

A competitividade se apresenta como uma necessidade ante o 'mercado' de trabalho, porém o conflito presente na fala dos entrevistados evidenciou que eles a consideravam uma característica de caráter mais negativo, como pudemos observar a seguir:

(...) acredito que sou competitiva, mas eu ajudo as pessoas, eu sou competitiva até certo ponto (Azul).

Eu sou competitivo, mas não ao ponto de passar por cima de ninguém, tem que ter limite (Azul-marinho).

É preciso querer ser melhor sempre, mas não é saudável passar por cima de todo mundo por conta disso, né? (Rosa).

Os gatilhos que geram conflitos internos têm sua origem nos desejos, ambições, sonhos e objetivos pessoais. Cria-se uma imagem ideal acerca dos sentimentos que nos fazem sentir bem, frustrando-se quando o contrário acontece no convívio dos amigos, sociedade e nas relações estabelecidas com os outros em geral. Estas frustrações podem desenvolver traumas e desencadear um gatilho para o estabelecimento de um conflito ou sofrimento (Lucas, 2013).

Os mecanismos de defesa são provenientes do ego, pois este representa o polo defensivo da personalidade. Diante de eventos que provocam a ansiedade e a necessidade de proteção, a negação é um dos mecanismos mais comuns a ser acionado. A negação se dá pela não concordância ou desagrado da realidade externa e se manifesta por meio da fantasia ou do comportamento (Melo et al., 2013; Borges e Peres, 2013). 
A competição não existe (...) só em relação a conseguir um melhor currículo, em relação a correr atrás de projeto de pesquisa, projeto de extensão e não comunicar a todos, fica uma coisa mais individual, para cada um (Branco).

Não, e não gosto disso (Salmon).

Não me considero competitivo, porém não consigo neste momento justificar (Prata).

Como podemos ver, a exclusão e a omissão foram características também presentes nas falas a seguir. Nota-se que 'trazer' os que estão mais próximos significa restringir a informação a um grupo seleto, mesmo aparentando ser uma atitude nobre. Há explícita uma necessidade de excluir uns para minimizar a concorrência e ampliar as possibilidades de conquista de um grupo delimitado e escolhido.

Me considero competitiva não, pois quando sei de algo que pode me beneficiar, procuro avisar as pessoas que convivem comigo, pelo menos (Verde).

Todo projeto que eu participo estou sempre buscando trazer as pessoas comigo. Agora, claro, trago as pessoas que são mais próximas, porque nunca se tem proximidade com todo mundo (Branco).

Entretanto, conhecendo os princípios e valores desse mundo competitivo, é possível conjecturar que trazê-los para perto, avisá-los de alguma forma, mesmo que inconscientemente, reflete a sensação de superioridade ou o sentimento de não se estar exposto a uma ameaça que possa comprometer a futura e possível conquista, pois se assim houvesse talvez o comportamento fosse também excludente.

A sensação que o discurso neoliberal traz é de que a liberdade individual, quando estimulada pela competitividade e exposta às mesmas oportunidades, pode impulsionar o indivíduo a conquistar seu 'lugar ao sol'. Desta feita, seu sucesso ou insucesso social e no mercado de trabalho está condicionado ao esforço individual, mérito ou ausência dele (Ribeiro, 2015). Esse individualismo também foi destacado nas falas:

As pessoas que correm atrás de um melhor currículo para o mercado de trabalho (...) criam atrito entre os colegas e terminam sendo muito individualistas nessa questão (Branco).

Existe uma individualidade, cada um se preocupa em ser melhor do que o outro. Isso pode contribuir ainda mais para a desunião da classe. Não deveria ocorrer na formação acadêmica, pois se durante a formação já há competitividade, imagine no campo profissional, no mercado de trabalho (Bronze). 
Constatou-se também que o conflito apresentado nas falas estava relacionado às atitudes e posturas assumidas diante de uma situação competitiva, principalmente das exigências do 'mercado de trabalho', em que as relações que se estabelecem na equipe são minadas e comprometidas por sentimentos de individualismo, egocentrismo e superação do outro. Ao mesmo tempo, o conflito evidencia a íntima relação entre 'mercado de trabalho' e os princípios do capitalismo, como podemos ver a seguir:

Acabamos destruindo laços por conta disso (competitividade). Eu observo que muitas pessoas gostam da mesma área que eu, é competitivo, mas é preciso não deixar isso se tornar uma guerra, atrapalhar o convívio não dá (Lilás).

A competitividade gera bloqueio nas relações, deixa-se o coletivo de lado (Cinza).

A construção do trabalho em equipe requer interação, respeito, comunicação, capacidade altruísta, valorização dos diferentes conhecimentos, experiências e habilidades dos envolvidos visando ao alcance dos objetivos e metas comuns. Quando passa a ser entendido como uma imposição, individualizado e fragmentado, inevitavelmente o trabalho em equipe gerará conflitos, com reflexos negativos no âmbito das relações (Duarte e Boeck, 2015).

Ao considerar que a categoria da enfermagem desenvolve um trabalho eminentemente coletivo e em equipe e carrega um de seus legados históricos, a divisão social do trabalho desde a época de Florence Nightingale, ${ }^{6}$ precursora da Enfermagem no mundo, torna-se ainda mais relevante e necessária a construção desses valores e habilidades relacionais.

Nossa profissão é de trabalho em equipe, e a gente precisa ser generoso, porque senão, não temos respeito, autoridade, nada. Se você chega para sua equipe de enfermagem e se mostra superior porque é enfermeira formada, você não vai conseguir que sua equipe trabalhe bem (Azul).

É evidente que em qualquer categoria profissional os conflitos e a ausência de integração e ajuda mútua trazem bastante insatisfação e descontentamento entre os trabalhadores. Além disso, a enfermagem vem sofrendo grande pressão e desgaste excessivo, física ou psicologicamente fato que pode ser explicado em parte pela grande concorrência que se apresenta hoje no 'mercado de trabalho', a busca por melhores condições de vida aliada aos descontentamentos com a profissão, massificante jornada de trabalho, precarização e multiplicidade de vínculos (Cardozo, 2015; Gomes et al., 2012).

As falas a seguir, entretanto, mostraram uma confusão entre esse reforço positivo e comportamentos não desejáveis entre outras categorias, que vão de 
encontro aos princípios éticos e morais, evidenciando o conflito de entendimento, sentimento e visão de mundo diante das diversas situações cotidianas enfrentadas.

Uma classe precisa estar unida para lutar pelos seus direitos. Um enfermeiro tem que desejar que seu colega seja tão bom quanto ele, pois só com bons profissionais conseguiremos nosso reconhecimento. (...) e lutar pelos nossos direitos (Marrom).

Acho que a competitividade tem uma influência negativa, não é por menos que nossa classe está do jeito que está (...) Aqui, se a gente erra, todo mundo cai em cima, mete o pau mesmo para deixar a situação pior do que já está, ao contrário de outras classes profissionais (Vinho).

Nesse contexto, Gomes e Ramos (2014) propõem o debate sobre ética em torno do comprometimento desvelado no discurso profissional, que parece peça-chave na contemporaneidade e mantém relação com alguns aspectos das transformações contemporâneas: precariedade nas relações de trabalho; luta pela ascensão profissional a qualquer custo, geradora de uma subjetividade competitiva entre pares; egoísmo narcísico acima de possibilidades de comprometimento relacional.

Compreende-se que o ambiente passa a ser reflexo das características específicas que assume, nas relações sociais e de poder que se estabelecem no convívio entre os pares, com suas influências particulares e individuais no modo de construir o consenso. Nesse sentido, no tocante à questão de gênero, a enfermagem permanece eminentemente feminina. Esta característica, na visão dos entrevistados da pesquisa, pareceu contribuir para a exacerbação da competitividade.

A enfermagem não é corporativista. O corporativismo é uma característica natural masculina, o que não impede de mulheres apresentarem essa característica, porém quando um grupo ou classe é majoritariamente feminina, o corporativismo é substituído pelo desejo de superar o próximo (Vermelho).

No livro Sabotando a rainha da festa: a verdade sobre mulheres e rivalidade, há uma investigação pioneira sobre a rivalidade cor de rosa (Barash, 2006). Com base em entrevistas com mulheres de diferentes idades, descobriu-se que a competição entre as mulheres é mais viciosa porque é secreta. “Elas não são favoráveis umas às outras porque são treinadas desde cedo a competir" (Barash, 2006, p. 288). Constatou-se também que a tendência de rivalidade aumenta entre mulheres da mesma área de trabalho, por sofrerem as consequências de uma sociedade que alimenta uma cultura machista e patriarcal (Martino, 2011).

Por ser a maioria mulher, e eu acho que mulher é mais competitiva que o homem e gera aquela discórdia, aquela competitividade maior (Azul-marinho). 
O gênero feminino predomina, isso gera uma coisa que piora bastante (Vinho).

Nas últimas três décadas, o aumento do trabalho feminino e a história das mulheres brasileiras têm sido marcados por meio de conquistas que representaram uma mudança em todas as esferas de seu cotidiano, umas mais significativas e outras menos, porém todas necessitando ainda de ampliação e resistência (Barsted e Pitanguy, 2011), especialmente o resgate da sororidade entre as mulheres (Alves, 2014). Assim, as relações de competitividade que perpassam pela enfermagem podem ser reflexo dessas condições de gênero que historicamente estiveram associadas ao sexo feminino (Cacciari et al., 2013).

\section{Conclusão}

Percebeu-se que a competitividade faz parte do cotidiano dos estudantes na graduação em enfermagem, tanto no ensino público quanto no privado. O comportamento competitivo foi considerado como uma característica inerente ao ser humano e pode ser aguçado diante do contexto de uma vida, dos diversos ambientes em que o estudante vivenciou a competitividade ou a construção de seus princípios e valores no seio da família e na formação.

Vale a pena ressaltar que o estímulo dos professores, as metodologias adotadas e os sistemas de avaliação também foram identificados como determinantes para o surgimento e o aprofundamento do comportamento competitivo na vida pessoal e profissional do futuro enfermeiro.

Inegavelmente, foi possível reafirmar que o sistema capitalista como modelo econômico vigente imprime seus valores, os quais são reproduzidos nas relações pessoais, sociais e de trabalho, a ponto de serem incorporados e confundidos como parte das características pessoais e humanas dos próprios estudantes, gerando muitas vezes um grande conflito ao afugentar suas subjetividades. Tal conflito se expressa pela naturalização da competitividade entre os sujeitos do estudo, indiferença e intensificação dos comportamentos excludentes e desumanizantes no convívio social no ambiente da formação.

Por fim, a competitividade é entendida como uma necessidade diante do 'mercado de trabalho', mas a grande maioria dos entrevistados a considera como uma característica ou condição negativa para a pessoa, nas relações que se estabelecem em sociedade e consequentemente para a enfermagem, como categoria que é eminentemente feminina - o que fatalmente potencializa essa competitividade por ser uma característica mais presente nas mulheres e ter no trabalho coletivo e compartilhado seu princípios fundantes. 


\section{Colaboradoras}

Nathalia Medeiros Martins foi responsável pela coleta de dados, redação, revisão e formatação do artigo. Danielly Santos dos Anjos Cardoso, Laís Miranda Crispim Costa e Regina Maria dos Santos contribuíram com a redação, revisão e formatação do artigo. Laíze Samara dos Santos realizou a coleta de dados e participou da redação e revisão do manuscrito.

Resumen El estudio que le dio origen a este artículo fue de tipo cualitativo, exploratorio y descriptivo, con el objetivo de estudiar la vivencia de la competitividad por parte del estudiante de pregrado de enfermería. La recolección de datos se realizó en el período de marzo a mayo de 2015. Los sujetos fueron veinte estudiantes de pregrado en enfermería de dos instituciones de enseñanza superior de Maceió, Alagoas, Brasil. Se utilizó una entrevista semiestructura para el relevamiento de la información y el posterior análisis temático. La referencia teórica adoptada para el análisis de los datos partió de la concepción de competencia de Caniato y Rodrigues, que tiene sus bases teóricas y filosóficas en el psicoanálisis freudiano y en la teoría crítica de la Escuela de Frankfurt, en especial Adorno y Horkheimer. Se observó que la competitividad es parte de la vivencia de los estudiantes por ser considerada una característica inherente al ser humano, que naturalmente convive con ésta en el sistema capitalista. Este comportamiento competitivo puede ser aguzado en el pregrado de acuerdo con el entorno, la personalidad/carácter y situaciones experimentadas. Se constató la existencia de un conflicto, pues los estudiantes observan la competitividad como una necesidad frente al 'mercado' de trabajo, pero la consideraban una característica de índole más negativa.

Palabras clave educación en enfermería; comportamiento competitivo; enfermería.

\section{Notas}

${ }^{1}$ Universidade Federal de Alagoas, Maceió, Alagoas, Brasil.

$<$ natymedeiros@hotmail.com>

Correspondência: Rua Tereza de Azevedo, 1.017, Farol, CEP 57052-600, Maceió, Alagoas, Brasil.

${ }^{2}$ Universidade Federal de Alagoas, Maceió, Alagoas, Brasil.

$<$ danielly.anjos@esenfar.ufal.br>

${ }^{3}$ Universidade Federal de Alagoas, Maceió, Alagoas, Brasil.

<laís.costa@esenfar.ufal.br>

${ }^{4}$ Universidade Federal de Alagoas, Maceió, Alagoas, Brasil.

$<$ relpesantos@gmail.com>

${ }^{5}$ Universidade Federal de Alagoas, Maceió, Alagoas, Brasil.

<laizesamara13@gmail.com> 
${ }^{6}$ Florence Nightingale (1820-1910) foi uma destacada enfermeira inglesa. Criou a primeira Escola de Enfermagem da Inglaterra no Hospital Saint Thomas, em Londres, em 1901. Natural de Florença, na Itália, estudou no King's College de Londres. Em 1858, Florence escreveu dois livros sobre sua área de atuação: Administração hospitalar do exército e Comentários sobre questões relativas à saúde.

${ }^{7}$ Sororidade é a irmandade entre mulheres, que se reconhecem como próximas física e afetivamente. Priorizam uma à outra em relação aos homens, apoiando-se mutuamente.

\section{Referências}

ALVES, Simone S. Saberes das mulheres veteranas na economia solidária: sororidade a outra educação!. 173f. Tese (Doutorado em Educação) - Universidade Federal do Rio Grande do Sul, Faculdade de Educação, Porto Alegre, 2014. Disponível em: <http://www.lume.ufrgs.br/ bitstream/handle/10183/104457/000939866. pdf? sequence $=1>$. Acesso em: 28 jun. 2017.

ANJOS, Danielly. Os cursos de graduação em enfermagem de Maceió/AL: um olhar complexo sobre os projetos pedagógicos. 143f. Dissertação (Mestrado em Enfermagem) - Escola de Enfermagem e Farmácia, Universidade Federal de Alagoas, Maceió, 2013.

BARASH, Susan S. Tripping the prom queen: the truth about women and rivalry. First edition. New York: St. Martin's Press, 2006.

BARSTED, Leila L.; PITANGUY, Jaqueline. O progresso das mulheres no Brasil 2003-2010. Rio de Janeiro: Cepia; Brasília: ONU Mulheres, 2011.

BAZZI, Munir. Despojamento na superação da competitividade. Revista Conscientia, Foz do Iguaçu, v. 8, n. 3, p. 161-168, jul.-set. 2009.

BISSOLI, Michelle de F. Desenvolvimento da personalidade da criança: o papel da educação infantil. Psicologia em Estudo, Maringá, v. 19, n. 4 p. 587597, out.-dez. 2014. Disponível em: <http://www. scielo.br/pdf/pe/v19n4/1413-7372-pe-19-04-00587. pdf $>$. Acesso em: 4 jul. 2017.

BORGES, Gizelle M.; PERES, Rodrigo S. Mecanismos de defesa em pacientes oncológicos recidivados: um estudo clínico-qualitativo. Psicologia em Pesquisa, Juiz de Fora, v. 7, n. 2, p. 171-179, jul.-dez. 2013.

VALLE, Ione R. O lugar da educação (escolar) na sociologia de Pierre Bourdieu. Revista Diálogo Educacional, Curitiba, v. 13, n. 38, p. 411-437, jan.-abr. 2013.

CACCIARI, Pâmella et al. Caracterização sociodemográfica e ocupacional de trabalhadores de enfermagem readaptados e readequados. Revista Enfermagem Uerj, Rio de Janeiro, v. 21, n. 3, p. 318-323, jul.-set. 2013.

CANEVER, Bruna P. et al. Processo de formação e inserção no mercado de trabalho: uma visão dos egressos de enfermagem. Revista Gaúcha de Enfermagem, Porto Alegre, v. 35 , n. 1, p. 87-93, mar. 2014.

CANIATO, Ângela M. P.; RODRIGUES, Samara M. A construção psicossocial da competição: o engano na cumplicidade de uma falsa vida. Psicologia \& Sociedade, Belo Horizonte, v. 24, n. 1, p. 23-35, jan.-abr. 2012.

CARDOZO, Eduardo G. et al. A insatisfação profissional na enfermagem: problemas psicossociais. Revista Rede de Cuidados em Saúde, Rio de Janeiro, v. 9, n. 2, p. 1-4, 2015.

CARVALHO, José R. C. A cooperação através das atividades físicas. 22f. Monografia (Especialização em Educação Física Escolar) - Departamento de Educação Física e Desportos, Universidade Federal Fluminense, 2009. 
CASTRO, Jorge A. Política social e desenvolvimento no Brasil. Economia e Sociedade, Campinas, v. 21, número especial, p. 1.011-1.042, dez. 2012.

COAN, Marival. O que revelam os slogans na política educacional. In: EVANGELISTA, Olinda (org.). O que revelam os slogans na política educacional. 1. ed. Araraquara/ SP: Junqueira\&Marin, 2014. p. 116.

DUARTE, Maria L. C.; BOECK, Jocemara N. O trabalho em equipe na enfermagem e os limites e possibilidades da Estratégia Saúde da Família. Trabalho, Educação e Saúde, Rio de Janeiro, v. 13, n. 3, p. 709-720, set.-dez. 2015.

FERNANDES, Josicelia D. Expansão de cursos/ vagas de graduação em enfermagem e a qualidade do processo de formação da(o) enfermeira(o). Revista Brasileira de Enfermagem, Brasília, v. 65, n. 3, p. 395-396, maio-jun. 2012.

FERREIRA, Maria A.; LATORRE, Maria R. D. O. Desigualdade social e os estudos epidemiológicos: uma reflexão. Ciência \& Saúde Coletiva, Rio de Janeiro, v. 17, n. 9, p. 2.523-2.531, 2012.

FREITAS, Vanessa C. S.; LIMA, Sérgio R. R. A respeito do princípio de que os interesses egoístas geram benefícios sociais: uma análise contemporânea. In: SEMANA DO ECONOMISTA, 3., Ilhéus, 2013. Disponível em: <http:// www.paece.com.br/semanaeconomista2013/ anais_2013/GT9_pensamento_economico_e_economia_brasileira/3-A_RESPEITO_DO_PRINCIPIO_DE_QUE_OS_INTERESSES_EGOISTAS_GERAM.pdf $>$. Acesso em: 10 jan. 2016

GOMES, Andréia P. et al. Atenção primária à saúde e formação médica: entre episteme e práxis. Revista Brasileira de Educação Médica, Rio de Janeiro, v. 36, n. 4, p. 541-549, out.-dez. 2012.

GOMES, Doris; RAMOS, Flávia R. S. Ética e comprometimento do profissional da saúde pós-reestruturação produtiva numa região metropolitana do Sul do Brasil. Interface: Comunicação, Saúde e Educação, Botucatu, v. 18, n. 49 , p. 1-12, abr.-jun. 2014.
GUARESCHI, Ana P. D. F.; KURCGANT, Paulina. Influência da formação docente no perfil do egresso de graduação em enfermagem. Cogitare Enfermagem, Curitiba, v. 19, n. 1, p. 101-108, jan.-mar. 2014.

INSTITUTO NACIONAL DE ESTUDOS E PESQUISAS ANÍSIO TEIXEIRA (INEP). A trajetória dos cursos de graduação na área da saúde: 1991-2004. Organizado por Ana E. Haddad et al. Brasília: INEP, 2006. p. 22-70. Disponível em: <http:// portal.inep.gov.br/documents/186968/484184/ $\mathrm{A}+$ trajet $\% \mathrm{C} 3 \% \mathrm{~B} 3 \mathrm{ria}+$ dos + cursos + de + gradua $\%$ C $3 \%$ A $7 \%$ C $3 \%$ A $30+$ na + sa $\%$ C $3 \%$ BAde + 1991-2004+Enfermagem/9b2d514a-2dfe-4f04-aae3-21746974ed7f?version $=1.2>$. Acesso em: 20 nov. 2015.

LUCAS, Miguel. Sobriedade emocional: não fique refém dos seus conflitos internos. São Paulo: Escola Psicologia (sítio), 2013. Disponível em: <http://www.escolapsicologia.com/ sobriedade-emocional-nao-fique-refem-dos-seus-conflitos-internos/>. Acesso: 12 nov. 2015.

MARTINO, Renato D. Por que as mulheres são tão competitivas entre si?. São Paulo: Pensar-se a si mesmo (sítio), 2011. Disponível em: < http:// pensar-seasi-mesmo.blogspot.com.br/2011/08/ por-que-as-mulheres-sao-tao.html> . Acesso em: 4 out. 2015

MATTOS, Laura V. Alfred Marshall: o capitalismo e sua utopia social. Economia e Sociedade, Campinas, v. 20, n. 3, v. 43, p. 637-659, dez. 2011.

MELO, Adriana F. V. et al. A importância do acompanhamento psicológico no processo de aceitação de morte. Estudos e Pesquisas em Psicologia, Rio de Janeiro, v. 13, n. 1, p. 152-166, 2013.

MELO, Alessandro. O projeto pedagógico da Confederação Nacional da Indústria para a educação básica nos anos 2000. 256f. Dissertação (Doutorado em Educação) - Faculdade de Educação Universidade Federal do Paraná, Curitiba, 2010.

MÉSZÁROS, István. A educação para além do capital. 2. ed. São Paulo: Boitempo, 2008. 
MINAYO, Maria C. S. O desafio do conhecimento: pesquisa qualitativa em saúde. 12. ed. São Paulo: Hucitec, 2010.

OLIVEIRA, Marcus A. T. Educação física escolar: formação ou pseudoformação? Educar, Curitiba, n. 16, p. 11-26, 2010.

PEREIRA, Luiz C. B. Uma alternativa para o capitalismo? Estudos Avançados, São Paulo, v. 28, n. 80 , p. 289-294, jan.-abr. 2014.

PERUZZO, Alice S. et al. Estresse e vestibular como desencadeadores de somatizações em adolescentes e adultos jovens. Psicologia Argumentada, v. 26, n. 55, p. 319-327, out.-dez. 2008.

POSSOLI, Gabriela E. O capitalismo no contexto das novas tecnologias e a reconfiguração da subjetividade e das relações humanas. In: EDUCERE, CONGRESSO NACIONAL DE EDUCAÇÃO, 3., 2005, Curitiba. Anais... Curitiba: Pontifícia Universidade Católica do Paraná, 2005. p. 1-12. Disponível em: <http://www.pucpr.br/eventos/ educere/educere2005/anaisEvento/documentos/ com/TCCI039.pdf>. Acesso em: 23 out. 2015.

RIBEIRO, Mardén P. O individualismo neoliberal como obstáculo à formação de professores na perspectiva da pedagogia crítica. Revista de Educação Educere et Educare, Cascavel, v. 10, n. 20 , p. $837-848$, jul.-dez. 2015.

ROBERTSON, Susan L. A estranha não morte da privatização neoliberal na Estratégia 2020 para a educação do Banco Mundial. Revista Brasileira de Educação, Rio de Janeiro, v. 17, n. 50, p. 283-302, maio-ago. 2012.
ROEHRS, Hellen; LENARDT, Maria H.; MAFTUM, Mariluci A. Práticas culturais familiares e o uso de drogas psicoativas pelos adolescentes: reflexão teórica. Escola Anna Nery Revista de Enfermagem, Rio de Janeiro, v. 12 , n. 2, p. 353-357, jun. 2008.

SCHERER, Susana S. A politécnica: compreensão e possibilidades para pensar a formação humana no campo escolar. In: SIMPÓSIO BRASILEIRO DE POLÍTICA E ADMINISTRAÇÃO DA EDUCAÇÃO, 26., 2013, Recife. Anais... Recife: Anpae, 2013. Disponível em: <http:// www.anpae.org.br/simposio26/1comunicacoes/ SusanaScherer-ComunicacaoOral-int.pdf $>$. Acesso em: 12 nov. 2015.

SILVA, Danielle S.; SILVA, Tarcisio T. Jogos cooperativos como ferramenta de desenvolvimento de equipes. Revista de Ciências Gerenciais, Valinhos, v. 15, n. 21, p. 137-152, 2011.

SOUSA, Jociele F. A. O modo de produção capitalista e a subjetividade individualista subjacente: reflexos sobre a espacialidade urbana. Mnemosine, Rio de Janeiro, v. 8, n. 2, p. 70-95, 2012.

SOUSA, Leilane B.; BARROSO, Maria G. T. Reflexão sobre o cuidado como essência da liderança em enfermagem. Escola Anna Nery Revista de Enfermagem, Rio de Janeiro, v. 13, n. 1, p. 181-187, jan.-mar. 2009.

Recebido em 11/03/2016

Aprovado em 21/09/2016 